\title{
Modelos de Reputação Internacional e Paradigmas de Política Externa*
}

Sabrina Evangelista Medeiros**

\section{Sobre o Valor da Cooperação Internacional}

Cooperação internacional é um tema que, no âmbito da ciência política, está tipicamente relacionado com a capacidade dos atores de estabelecer, em ação mútua e de confiança, relações vantajosas que são qualificadas como absolutas. A diferença fundamental entre este modelo e o competitivo, relacionado às crenças de tipo realista, está no fato de que, no segundo, o ganho é inversamente proporcional à perda do outro ator, em ambiente naturalmente anárquico, o que qualificamos como um tipo relativo de ganho (POWELL, 1991).

Nesse sentido, a caracterização de uma premissa cooperativista está associada a um sistema de confiança mútua em que os atores, ao não estimarem o potencial fim da relação, têm preferência pela confiança porque, desse modo, garantem ganhos constantes, associados à evolução dos laços cooperativos (AXELROD, 2000). Jogos de interação como esse supõem um valor de confiança que é o que determina, em última instância, o resultado positivo da cooperação. Neste caso, o re-

\footnotetext{
* Artigo recebido em $1^{\circ}$ de junho de 2011 e aceito para publicação em 11 de dezembro de 2011.

** Doutora em Ciência Política pelo Instituto Universitário de Pesquisas do Rio de Janeiro (Iuperj) e professora adjunta de Relações Internacionais da Escola de Guerra Naval da Marinha do Brasil (EGN/MB) e do Programa de Pós-graduação em História Comparada da Universidade Federal do Rio de Janeiro (PPGHC/UFRJ). E-mail: sabrinamedeiros@yahoo.com.
} 
sultado positivo associa-se ao fato de que este é individualmente melhor do que antes, e não em relação aos resultados do seu parceiro, em outras circunstâncias, competidor.

Estratégias tit-for-tat $^{1}$ qualificam-se exatamente por movimentos de cooperação que se seguem aos primeiros, podendo criar um círculo de confiança que se traduz em reputação. Com efeito, a reputação de um ator em estratégia cooperativa é a medida pela qual os demais atores qualificam sua confiança no primeiro (AXELROD, 2000).

Se observarmos, no âmbito institucional o modelo de cooperação exposto cria fontes de reputação associadas à capacidade dos atores de agirem de acordo com compromissos firmados em ambiente cooperativo. Neste caso, a reputação é garantida não somente pela crença no resultado cooperativo por meio da confiança que expressam os próprios atores, mas também pela capacidade que têm de agir de acordo com os compromissos, depois de firmados. Andrew Guzman (2006, 2008, 2011) levantou indagações a respeito da capacidade dos atores de agirem de acordo com base na reputação internacional, proporcionando o cruzamento das teorias de Relações Internacionais com o direito internacional. $\mathrm{O}$ avanço da categoria reputação - na expressão de Guzman (2008, p. 72), para efeito do cumprimento de acordos futuros - trata de permitir aos demais atores qualificar um determinado Estado positiva ou negativamente. Por outro lado, se esses compromissos não podem ser historicamente verificáveis, certamente a reputação não será um condicionante da cooperação e, tampouco, dos resultados desta.

Rachel Brewster (2009, p. 327) aponta uma lacuna nesta teoria quanto aos efeitos que determinado partido, ideologia ou governo podem ter em relação a um acordo. Isso porque Brewster destaca que determinados governos podem levar mais ou menos em conta a reputação historicamente conquistada por um Estado, reconhecendo que, para Guzman, a reputação pertence aos Estados. Em contrapartida, a relevância da crítica de fragilidade da reputação dos Estados por meio do peso que têm os governantes é diminuída ao observarmos que a reputação historicamente constituída também gera um custo de mudança para o governante e se atrela a uma constância mais razoável para a política externa do que para as demais políticas públicas. 
Shiping Tang (2005, p. 36) reconhece que a reputação é um valor atribuído pelos próprios políticos aos Estados, que estão tanto focados em estabelecer acordos com base nesta quanto voltados a conquistá-la. Ainda que Tang verifique uma divisão entre os que creem na reputação como um valor a ser considerado e os que não creem que a um Estado seja possível desejá-la em um sistema impreciso e imperfeito, ambas as tendências convergem quanto ao reconhecimento de que existe um valor em jogo, fundamentalmente, para efeito de cooperação. Nessa literatura, o ponto que desejo destacar é que outro tipo de reputação, que não é conquistada pelo alto grau de confiança e que compete às capacidades de um Estado, não está envolvido com o direito internacional e está imperfeitamente absorvido pelas proposições apresentadas.

A valorização de interesses individuais, de natureza competitiva, em detrimento dos interesses cooperativos pode ser determinante para a perda de reputação quanto ao esquema institucional no ambiente internacional, em que pese a fidelidade dos atores aos arranjos e regras comuns. Levando-se em conta que, quanto ao direito internacional, os atores estão livremente associados por meio de tratados e compromissos de menor nível de fidelização, o imperativo da confiança poderia estar minimizado perante as fases anteriormente necessárias a um arranjo de jurisdição internacional. Em contrapartida, apesar da voluntariedade natural dos arranjos no direito internacional, observamos que Estados são compelidos a cooperar, o que pode derivar dos diversos eixos de interesse associados de forma indireta àquele compromisso em questão.

Desse modo, nem sempre um compromisso se dá por uma vantagem amplamente esperada e localizada nele, mas em outros compromissos estratégicos, às vezes informais, que estão indiretamente associados àquele, por meio de parceiros potenciais. Neste caso, a ideia de reputação está ampliada porque pertence a uma diversidade de interesses, regidos por uma complexa rede de alianças e hierarquias. Barbara Walter (2006, p. 314-315) pondera que a literatura a respeito do tema pouco teria dado atenção às expectativas dos Estados em relação às futuras repercussões de seus atos. Para a autora, evitar a guerra pode 
ser um dos elementos fundamentais utilizados para explicar o quanto os custos futuros podem representar um comportamento de menor retaliação e agressividade antes. Ao mesmo tempo, Walter considera que uma decisão em uma direção mais ostensiva antes pode ser gerada também como garantia de um futuro visto como repetidamente de conflito, o que, em última instância, obriga o ator a ponderar sobre um futuro ciclotímico, dotado de repetidas crises. Assim, faz-se cumprir a necessidade de um direcionamento do comportamento futuro de terceiros como no caso estudado por Walter a respeito dos grupos separatistas, em que vigora preponderantemente a necessidade do governo de, por vezes, garantir o exemplo de um comportamento em razão de outros casos futuros.

Ou seja, para efeito tanto do comportamento doméstico de um governo em relação a uma fonte de conflito quanto do processo decisório de política externa em relação a um futuro litígio, é mister a história do comportamento de um ator para sua reputação diante dos demais no futuro. Não há dúvida, pois, de que as relações cooperativas expressam uma teia de participantes cujos interesses são múltiplos e mais ou menos variáveis de acordo com o seu peso e sua vantagem cooperativa. No tocante às vantagens reside o nó que interpela neorrealistas e neoinstitucionalistas: existe uma hierarquia de valores que estão associados aos parceiros, tanto relacionada à reputação ligada à confiança, quanto à reputação por liderança, ou seja, voltada à autonomia perante os resultados cooperativos complexos em âmbito internacional.

\section{Reputação Cooperativa e Reputação por Liderança}

Ao que chamo de reputação cooperativa, atribuo o valor de confiança que outros parceiros têm em um determinado ator. De outro modo, a reputação de liderança é aquela que um ator possui no sistema internacional, garantida pelo respeito que os demais partícipes têm, garantida pela autonomia decisória que possui. Enquanto a reputação cooperativa é baseada nos princípios regidos pelo direito internacional, a reputação de liderança é orientada segundo a autonomia de que usufrui um determinado ator, comumente alinhada à sua posição de força no sis- 
tema internacional. Note-se que a reputação pode ser tanto negativa quanto positiva, e, em ambos os casos, é retratada pelos outros atores.

Para efeito do que chamei de reputação cooperativa, são relevantes a confiabilidade que o ator produz e os dados que, observados pelo potencial parceiro, expressam o cumprimento do combinado por parte deste (compliance) (TOMZ, 2007, p. 230-231). Para esse fim, a teoria da reputação associada aos mercados e à robustez do crédito público nos serve porque qualifica a reputação por meio da experiência de um determinado parceiro, ao mesmo tempo em que também têm importância as condições objetivas contemporâneas ao ato cooperativo.

De outro modo, para efeito da reputação por liderança, a componente militar é variável determinante para a garantia de autonomia. Porque mais centrada em ganhos relativos, a reputação por liderança é fomentada por princípios individualmente construídos, baseados tanto em domínios internacionais quanto na audiência interna, ou seja, no valor atribuído à liderança por seus nacionais. Fearon (1994) chamou os custos relacionados à reputação internacional no âmbito doméstico de audience costs ("custos de audiência"), demonstrando que os Estados buscam permanentemente manter sua reputação internacional, com efeito, em relação às ameaças à defesa e ao povo, por meio do receio de perda da reputação em âmbito nacional. Isso nos permite relacionar os custos de audiência à elegibilidade nacional e à qualificação da importância das relações exteriores à liderança pessoal e partidária em cenário democrático.

Quanto à capacidade de cooperar e estabelecer confiança, a proximidade de sistemas legais e institucionais entre parceiros tende a aumentar a possibilidade de transparência da cooperação. Nesse espectro, Emilia Powell (2006) defende que a paridade de modelos institucionais domésticos (prioritariamente entre modelos democráticos) aumenta a capacidade de cooperar e legitimar experiências cooperativas no âmbito externo. Da mesma forma, Estados que têm legislações e compromissos morais de valor igual ou próximo tendem a ser mais confiáveis no tocante às organizações internacionais, porque mais suscetíveis à adesão e firmamento de compromissos exteriores junto ao seu sistema doméstico legal. 
Nesse sentido, os compromissos podem ser qualificados como semiformais ou formais - à luz do direito internacional, soft law e hard law (SZÉKELY, 1997, p. 175-176). Se ambos os ambientes são passíveis do estabelecimento de relações de confiança e desconfiança, soft ou hard, os atos de cooperação não tradicionais ou tradicionais fazem vigorar desejos estratégicos igualmente importantes para os sujeitos em questão.

Emerge, assim, a variedade de desejos e ações estratégicas embebidas da ampliação ou manutenção do status quo de um ator no sistema internacional. No lugar do status quo, cujo sentido é insuficiente e abstrato, Estados buscam garantir níveis de reputação que lhes permitam garantir que seus ganhos sejam constantes e permanentes. Em última instância, uma alta reputação lhes garantirá o usufruto de amplo status quo. Contudo, é a reputação o condicionante do status quo, porque dela deriva a confiança e a capacidade de manobra e barganha, antes e depois de um acordo estratégico, formal ou informal, nas relações internacionais.

\section{Usos Estratégicos da Reputação}

Um ponto importante no debate a respeito da reputação internacional que um Estado tem é a mensuração da capacidade de um tratado ou acordo informal ser efetivo. Esta efetividade, traduzida pelo cumprimento (compliance), está amplamente relacionada à reputação de um Estado. Nesse caso, trata-se de reputação cooperativa, que é um condicionante tanto dos Estados mais fortes quanto dos mais fracos. Em contrapartida, o histórico de relações de confiança e de traições é, certamente, mais expressivo ainda para os dois grupos, fortes e fracos, pela manutenção do status quo para os primeiros e pela possibilidade de ascensão para os demais (DOWNS; JONES, 2002).

Outro aspecto é a própria consciência da reputação, o que implica em um valor maior ou menor da qualificação dos parceiros em potencial por um determinado Estado. Este valor, sem dúvida, é um atributo muito mais importante no tipo de reputação cooperativa, porque a finalidade desta é a confecção de vantagens absolutas para todas as partes, embora eventualmente desiguais entre si. Neste caso, se a consci- 
ência da reputação de um ator é menor ou se suas estratégias não implicam na presença de uma reputação positiva, não será este um modelo de política externa associado à cooperação como modelo de estabilidade das relações internacionais.

Seja este modelo reputacional cooperativo ou não, vigora aqui a premissa de que o processo decisório dispõe concomitantemente de efeitos gerados tanto pelo Estado, quanto pelo seu executivo/governo e seus governantes (citando os três modelos de processo decisório de Allison (1969)), uma vez que este é o mecanismo principal do efeito reputacional ora discutido. Portanto, é reconhecido que nem sempre o ambiente internacional onde ocorrem estas relações será dotado de princípios cooperativos, exatamente porque estes são dependentes das estratégias de cada Estado. Neste caso, nem sempre que um Estado falta em termos de confiança ou tem grandes chances de trair ele terá margem para a conquista de uma reputação baseada na liderança, pois a sua liderança dependerá exclusivamente das capacidades de que dispõe em relação aos seus recursos naturais, militares e econômicos, fundamentalmente. Assim, é imprescindível compreender o nível de dependência e autonomia que usufrui um Estado no sistema internacional.

Para o entendimento da forma de reputação de que usufrui um ator, ainda é importante ressaltar o modelo de compromisso cooperativo em questão. A literatura, majoritariamente, (KEOHANE, 1984; AXELROD, 1984; NORTH, 1994) aponta para um modelo contemporaneamente descentralizado de cooperação, em que as bases estão voltadas para um sistema de dependências múltiplas, diversificadas, fundamentadas por um conjunto de interseções. Nesse ambiente, a reputação é preponderante exatamente porque os compromissos firmados são mantidos tendo em vista outros compromissos estratégicos, cujo sistema de confiança está em risco a partir do primeiro rompimento ou fragilização (DOWNS; JONES, 2002, p. 113-114). O desafio associado à situação acima são os custos de oportunidade, uma vez que os incentivos não estão somente vinculados aos próprios eixos cooperativos (parceiros), mas aos terceiros também. 
Desse modo, Downs e Jones (2002) atribuem aos Estados mais de um valor de reputação, exatamente porque motivados por uma série de compromissos múltiplos. O que chamaram de reputação múltipla, qualifico aqui como reputação cooperativa porque, em contraste com a reputação por liderança, é fomentada pela acentuação de arranjos e por modelos de confiança de paridade, embora com níveis distintos de dependência e estreitamento. Recorrentemente, o encontro dos dois modelos de reputação é interpretado como uma função de um pelo outro. Assim, para grande parte dos internacionalistas do direito, a reputação tanto é a maneira pela qual um membro do sistema internacional se torna "honorável" (honorable member) (DOWNS; JONES, 2002) no que diz respeito ao grau de confiança, quanto os compromissos que evidencia. Com base nesse entendimento, o primeiro pode ser uma função do segundo (DOWNS; JONES, 2002). Em contrapartida, qualifico o modelo aqui exposto de construção de reputação como fundado em dois modos de garantia distintos, ainda que Estados possam obter vantagens de ambos os espectros de reputação.

Isso quer dizer que Estados podem exercer sua reputação por liderança em momentos litigiosos, por exemplo, enquanto podem dispor de sua reputação cooperativa quando exercendo alianças estratégicas. Pontuase, assim, um elemento importante da estratégia reputacional de um ator, o que pode diferenciar países emergentes como o Brasil dos que já usufruem do reconhecimento do valor de potência, como os Estados Unidos: para o primeiro, a reputação cooperativa passa a ser um valor de reconhecimento sem igual no sistema internacional contemporaneamente; para o segundo, ao mesmo tempo que o sistema o obriga às relações de interdependência e ao consenso sobreposto do direito internacional (RAWLS, 2001a, 2001b, 2002), usufrui de liderança para fazer garantir os seus demais interesses estratégicos.

Para isso, o comportamento histórico de um ator é absolutamente relevante para ambos os paradigmas reputacionais (TOMZ, 2007; DOWNS; JONES, 2002). No primeiro caso, ainda que haja dificuldades de cumprimento de um tratado, a confiança estabelecida em outros momentos será determinante para a revisão do mesmo, enquanto, no segundo caso, também a história da preponderância de um ator pode 
Modelos de Reputação Internacional e Paradigmas de

Política Externa

causar uma eventual perda de reputação, classificada comumente como temporária ou ocasional.

De modo geral, a teoria dos jogos, particularmente quanto aos jogos repetitivos (tit-for-tat), nos garante que o modelo de reputação cooperativa é baseado na soma das múltiplas recepções da capacidade cooperativa de um ator pelos demais, o que está relacionado, em grande medida, à sua capacidade geral de cumprir um acordo. Mas, por outro lado, não é possível mensurar-se a capacidade de um ator garantir reputação por liderança se não levarmos em conta, não os eixos cooperativos, mas as suas capacidades, relativamente analisadas (em função dos seus competidores).

Portanto, em que pese o ganho de reputação de um ator, não é possível negar que, segundo este argumento, o contraste entre modelos de reputação ou a vantagem de um modelo sobre o outro para um mesmo ator (que se utiliza de ambos) tem diferentes pesos e consequências para o sistema internacional. Reconhecendo-se que não há dois sistemas distintos em operação, ambos os valores estão embutidos nas relações que Estados estabelecem, sendo alguns deles mais capazes de se relacionarem por uma das garantias reputacionais.

Cabe ainda ressaltar que a reputação é condição anterior e de continuidade de uma relação, seja ela de hegemonia e sobreposição ou de cooperação. Já a retaliação advém de princípio distinto: no caso da reputação por liderança, da ampla capacidade individual que tem o ator de retaliar; no caso da reputação cooperativa, da profundidade do direito (da soft à hard law) e da diversidade de atores envolvidos no pleito. Esta distinção vai ao encontro de Keohane (1984), na medida em que supunha que a violação de um acordo está envolvida com as expectativas recíprocas e com aquelas externas ao compromisso, porque mobilizam outros sujeitos para aquela ocasião ou outra distinta (KEOHANE; NYE, 1977; KEOHANE, 1984; HURREL, 2005). Ao que Downs e Jones chamam de imperfect reliability (confiabilidade imperfeita) quanto à capacidade cooperativa no sistema internacional entre Estados razoavelmente confiáveis, devemos vincular os princípios reputacionais dos mesmos: porque, se forem distintos os valores reputacionais, serão distintos os resultados e imperfeitas as soluções coope- 
rativas. James Rosenau (1961) qualificou que este ambiente, regido por processos decisórios complexos, de conflitos e revezada distensão, tem como base um sistema de interpenetração de poderes, atores e decisões em constante rearranjo. Como característica principal, o aspecto da governança é o que traz para este ambiente algo além do processo decisório do ator, em que impera sua capacidade de gerenciar os aspectos externos de sua existência no ambiente internacional.

A principal hipótese deste trabalho é qualificada não só pela distinção entre modelos de reputação: na dificuldade em se estabelecer princípios vantajosos confiáveis em determinado padrão cooperativo, formal ou informal, emerge sempre o desejo de detenção de capacidades para um futuro de preponderância de poder ou para a garantia de estabilidade. Assim, esta premissa é a de que Estados lutam por desejos de preponderância quando focados em reputação por liderança, ao mesmo tempo em que, focados em estabilidade, garantem-se por mecanismos associados à reputação cooperativa.

\section{Reputação e Relações de Poder}

Propondo uma analogia à tipologia de Barnett e Durvall (2005) sobre as relações de poder, defendo que o poder de tipo compulsório e o poder de tipo estrutural estão relacionados à reputação por liderança, enquanto o poder de tipo institucional e o poder de tipo produtivo estão relacionados à reputação cooperativa.

No poder compulsório, o domínio de um ator pelo outro se dá por meio material ou simbólico, em que o primeiro controla as ações do segundo. De outro modo, no usufruto de um poder de tipo institucional, os elementos de controle são dotados de institucionalidade e é por meio desta que o domínio é exercido. No segundo caso, o ambiente deve ser regido pela mesma regularidade, de modo que um instrumento institucional seja o mesmo pelo qual se exercerá poder sobre o outro. Domínios associados a poderes desiguais em um eixo cooperativo podem ser associados à reputação de tipo cooperativo porque sob o escopo de um regime institucional. Este é o caso de uma relação de poder em que pesa a hierarquia de sujeitos dentro de uma instituição, a 
exemplo da Organização do Tratado do Atlântico Norte (OTAN) e da União Europeia.

As relações internas estruturais, referentes às posições que ocupam agentes sociais, constituem o elemento mais importante de uma relação estrutural de poder, assim como as relações sociais também são relevantes para o modelo produtivo, embora de modo mais difuso. Em contrapartida, a diferença quanto à centralidade das relações de poder entre esses modelos leva o modelo estrutural a um paralelo com um modelo de reputação ligado à liderança (domínio estrutural classista); de outro modo, o modelo produtivo é voltado para a estabilidade e, em contrapartida à liderança, é focado em relações cooperativas (entre classes) - ainda que desiguais -, ampliando as relações de poder produtivas, baseadas em práticas e incentivos do próprio ambiente internacional (BARNETT; DURVALL, 2005).

Por outro lado, não é possível pensar que Estados estão isentos de um modo difuso de exercício de poder (produtivo). Dessa maneira, ainda que Estados se utilizem constantemente de ação coercitiva, obtendo o controle do comportamento de outros, algumas prerrogativas ambientais e sociais menos constantes os obrigarão a um rearranjo de seu controle sobre os demais, de forma a torná-lo menos aparente e mais aceitável. Portanto, podemos dizer que o poder institucional, assim como o poder produtivo, são forças relacionadas à diversificação, inclusive, nas relações internacionais. De outro modo, o poder compulsório e o estrutural residem em um tipo de dominação direta, porque única ou individual e menos sujeita ao ambiente. Em um sistema baseado progressivamente em interdependência, há uma tendência notável para que os poderes difusos, institucionais ou produtivos, fundados em uma reputação de tipo cooperativo em minha hipótese, sejam progressivamente mais utilizados.

A escolha por um exercício de poder, do ponto de vista estratégico, não se dá somente pela representação temporária, político-partidária, de um ator estatal, mas pelos seus compromissos nacionais, histórica e socialmente presentes. Assim, a reputação de um Estado é tanto construída pelo seu valor histórico como pelo seu comportamento no presente. De outro modo, o elemento histórico de um modelo de reputa- 
ção internacional não necessita de substituição total: ao tempo da institucionalização do sistema internacional, emergiu a reputação cooperativa, que hoje, sem dúvida, tem mais relevância do que antes.

Contudo, de forma inversa, um modelo estratégico que se utilize de reputação cooperativa predominantemente tem em vista outro paradigma de autoincorporação no sistema internacional, calcado na estabilidade. Ou seja, se para um Estado que já usufrua de reputação histórica é mais pertinente dizer que a reputação cooperativa é mais um elemento, para os que não a têm disponível, a reputação cooperativa pode ser um dos poucos meios de sua incorporação no sistema internacional com alguma relevância.

Do ponto de vista econômico, os custos de transação são a medida pela qual se pode mensurar os ganhos e perdas de uma relação comercial (NORTH, 1994). Para North, a institucionalização de processos (por meio de aparato legal, contratos, garantias e instituições regulatórias) serve às relações para torná-las mais intensas, impessoais e confiáveis. Com o crescimento das relações comerciais e do nível de complexidade das estruturas de cooperação no sistema internacional, a margem de autonomia dos Estados diminui, ao mesmo tempo que foram ampliadas as suas obrigações, diretas e indiretas, em relação aos seus parceiros. Como consequência, os custos de transação associados ao pertencimento aos subsistemas do ambiente internacional não deixam de fomentar a construção de uma reputação de tipo cooperativo, em associação ou não à sua reputação histórica, que pode ser calcada em liderança.

Mercer (1996, p. 36-39) argumenta, por outro lado, que algumas condições da reputação são invariáveis, fundamentalmente aquelas que dizem respeito aos inimigos de um ator, em que a questão reputacional não atuaria. De outro modo, se utilizarmos os argumentos de Mercer a respeito da observância de um comportamento como confiável ou não de acordo com os princípios do jogo de interesses, em que vigoram interesses competitivos, verificamos que sua crítica ao valor da reputação desconsidera a visão do ator de si mesmo e, assim, é orientada ao foco do valor do ator pelos demais. 
Neste âmbito, Mercer (1996) avalia como inconsistente a reputação e o ganho reputacional possível, em decorrência - que dependa de um ator em franca competição com o terceiro. Em contrapartida, tal face competitiva não deixa de estar permeada de valores difusos como aqueles voltados às relações de poder e de ganho relativo, imperativos da competição, pertinentes ao que defendemos como reputação por liderança. Neste caso, quanto à visão de si mesmo do ator, são relevantes os projetos individuais para efeito de sua projeção; do contrário, para efeito de ganho em sua reputação cooperativa, um ator tem como maior determinante a confiança gerada no ambiente expressa pelos demais, em maior grau do que sua própria visão de projeção, dotada de variáveis distintas das primeiras.

Thomas Schelling (1960, p. 86) já apontava esta distinção ao acentuar que:

Deve-se salientar que o jogo de coordenação pura é um jogo de estratégia, no sentido estritamente técnico. É uma situação em que a melhor escolha de comportamento e ação de cada jogador depende da ação que espera que o outro venha a realizar, que ele sabe que depende, por sua vez, da expectativa dos outros. Esta interdependência de expectativas é precisamente o que distingue um jogo de estratégia de um jogo de azar ou um jogo de habilidade. No jogo de coordenação pura, os interesses são convergentes; nos jogos de conflito puro, os interesses são divergentes.

Assim sendo, a hipótese central deste artigo é a de que, consolidando-se os modelos reputacionais dispostos na literatura, é possível avançar na proposição de uma classificação entre a reputação por liderança e a reputação cooperativa. Outro ponto é que a premissa da competição não está descartada para ambos os modelos; afinal, dizem respeito à competição internacional e à capacidade de Estados representarem seus interesses na esfera internacional. Esta vontade não se aniquila 
com estratégias distintas de pertencimento; apenas nos permite explicar que estratégias distintas ocupam os mesmos fóruns e que têm pesos distintos calcados na reputação de que usufruem, qualificada por terceiros. Modelos de reputação servem, portanto, aos interesses estratégicos de cada ator.

Nesse sentido, ao correlacionarmos a taxonomia de projeção de poder de Barnett e Durvall (2005) ao modelo de reputação aqui proposto (coercitivo e estrutural - reputação por liderança; institucional e produtivo - reputação cooperativa), encontramos uma relação estreita entre a institucionalidade internacional como forma de pertencimento (incluindo a diversidade de atores e interesses do sistema produtivo) e como exercício de liderança. Assim, se Estados são compelidos a participar das instituições de coordenação internacional (ABBOTT; SNIDAL, 1998), esta participação se dá de modo distinto, com base na reputação de que dispõem. Desse modo, se um padrão de projeção de poder estrutural está ligado à dominação das estruturas por um grupo, da mesma forma o padrão institucional faz vigorar o poder das instituições e processos. Em ambos os casos, o exercício da participação se dá, sendo este diversificado e cooperativo ou baseado na liderança.

\section{Conclusões}

Para efeito de uma reputação de tipo cooperativo, o valor essencial a ser observado é o aumento da inserção do ator pela ampliação de sua confiança como parceiro no sistema internacional. Ao mesmo tempo, é possível dizer que os Estados cujo modelo de inserção se deu historicamente por elementos de distinção, quais sejam, aqueles relacionados à preponderância, também não dispensam valores reputacionais que transitam pela órbita cooperativa, especialmente em ambiente de crise econômica e rearranjos institucionais constantes.

Dessa forma, não é possível imaginar que a política externa seria definida com base em uma finalidade permanente, mas em paradigmas gerais, mais ou menos variáveis e observáveis durante os próprios processos de tomada de decisão. Nessa proposta, a relação entre projeção de poder e reputação acontece de forma distinta para efeito de 
uma reputação cooperativa (de projeção difusa) e uma reputação por liderança (de projeção direta). Seguindo esse argumento, notamos que a reputação por liderança pode ser afetada pela reputação cooperativa se levarmos em conta um ambiente descentralizado de cooperação, gerido por uma lógica chamada P2P (peer-to-peer - par a par) de cooperação. Neste caso, vigoram princípios difusos porque a diversidade de relações estabelecidas por cada ator concomitantemente cria uma rede de cooperação descentralizada em sua forma e amplificada em suas alternativas.

Assim, sugere-se que é este o paradigma principal de potências médias e emergentes como o Brasil, porque a lógica de participação internacional preponderante atende aos seus interesses estratégicos por meio da lógica de cooperação P2P. Ao mesmo tempo, o ambiente internacional, mesmo que regido cada vez mais pela lógica $\mathrm{P} 2 \mathrm{P}$, tem sistemas de maiores custos de transação associados às disparidades entre parceiros. Não é possível, pois, pensar que Estados não usufruem largamente de suas capacidades para diminuir as suas eventuais desvantagens em um determinado eixo cooperativo. Assim, apesar da lógica $\mathrm{P} 2 \mathrm{P}$, o controle sobre o parceiro acontece por outros elementos em que se encontra vulnerável, direta ou indiretamente. Aqui chegamos ao conceito de Keohane (1986) de reciprocidade difusa, em que, continuamente, o sistema internacional tende a promover estabilidade por meio de uma reciprocidade continuada, não específica, em que há a comunhão de alguns valores gerais. Próximo ao que Rawls (2001a) qualificou como um consenso sobreposto, Keohane aponta para uma equivalência de valores entre partes que faz com que elementos ligados à reciprocidade específica (setorial) tenham menos peso.

Dessa forma, exercícios de liderança continuam a ter efeito sobre cada um dos eixos cooperativos que estabelecem um Estado, ou ainda para a formulação e cumprimento de normas gerais no sistema internacional em que vigore a finalidade de manutenção da estabilidade por meio do seu espaço de liderança. Estes não são, portanto, modelos absolutamente excludentes de reputação, porque regidos por estratégias e dependentes do sistema de interdependência, do aprofundamento 
institucional das relações internacionais, do direito internacional, do comportamento alheio, da manutenção da ordem e das tensões entre lideranças constituídas e ascendentes.

\section{Nota}

1 Podemos usar a seguinte expressão equivalente em português: "olho por olho, dente por dente".

\section{Referências Bïbliográficas}

ABBOTT, Kenneth; SNIDAL, Duncan. Why States act through formal international organizations. Journal of Conflict Resolution, v. 42, n. 1, p. 3-32, 1998.

ALLISON, Graham. Conceptual models and the Cuban missile crisis. American Political Science Review, v. 63, p. 689-718, 1969.

AXELROD, Robert. After hegemony: cooperation and discord in the world political economy. Princeton: Princeton University Press, 1984. p.105-108. $-151,2000$.

On six advances in cooperation theory. Analyse \& Kritik, v. 22, p. 130-

BARNETT, Michael; DURVALL, Raymond. Power in international politics. International Organization, v. 59, n. 1, p. 39-75, 2005.

BREWSTER, Rachel. The limits of reputation on compliance. International Theory, v. 1, n. 2, p. 323-333, 2009.

FEARON, James. Domestic political audiences and the escalation of international disputes. American Political Science Review, v. 88, n. 3, p. 577-592, 1994.

GUZMAN, Andrew. Reputation and international law. Georgia Journal of International and Comparative Law, v. 34, n. 2, 2006.

How international law works. Nova Iorque: Oxford University Press, 2008. 
Modelos de Reputação Internacional e Paradigmas de Política Externa

; MEYER; Timothy L. International soft law. Journal of Legal Analysis, v. 2, n. 1, p. 171-225, 2011.

HURRELL, Andrew. Power, institutions, and the production of inequality. In:

BARNETT, M.; DUVALL, R. (Ed.). Power in global governance. Cambridge: Cambridge University Press, 2005. p. 33-58.

JONES, Michael; DOWNS, George. Reputation, compliance and international law. Journal of Legal Studies, v. 31, n. 1, 2002.

KEOHANE, Robert. After hegemony: cooperation and discord in the world political economy. Princeton: Princeton University Press, 1984.

. Reciprocity in international relations. International Organization, v. 40, n. 1, 1986.

; NYE, Joseph. Power and interdependence. Boston: Little Brown, 1977.

MERCER, Jonathan. Reputation and international politics. Ithaca: Cornell University Press, 1996.

NORTH, Douglass. Transaction costs through time. The Economics Working Paper Archive, 1994.

POWELL, Emilia Justyna. Conflict, cooperation, and the world's legal systems. Tallahassee: The Florida State University, 2006.

POWELL, Robert. Absolute and relative gains in international relations theory. American Political Science Review, v. 85, n. 4, 1991.

RAWLS, John. Direito dos povos e razão pública revista. São Paulo: Martins Fontes, 2001a.

. O liberalismo político. São Paulo: Ática, 2001b.

. Uma teoria da justiça. São Paulo: Martins Fontes, 2002.

ROSENAU, James. Public opinion and foreign policy: an operational formulation. Nova Iorque: Random House, 1961.

SCHELLING, Thomas C. The strategy of conflict. Cambridge: Harvard University Press, 1960.

SZÉKELY, Alberto. Non-binding commitments: a commentary on the softening of international law evidenced in the environmental field. In: UNITED NA- 
TIONS. United Nations international law on the eve of the twenty-first century: views from the International Law Commission, le droit international à l'aube du XXe. siécle: réflexions de codificateurs. Nova Iorque: United Nations, 1997.

TANG, Shiping. Reputation, cult of reputation, and international conflict. Security Studies, v. 14, n. 1, 2005.

TOMZ, Michael. Reputation and international cooperation: sovereign debt across three centuries. Nova Jersey: Princeton University Press, 2007.

WALTER, Barbara F. Building reputation: why governments fight some separatists but not others. American Journal of Political Science, v. 50, n. 2, p. 313330, 2006.

\section{Resumo}

\section{Modelos de Reputação Internacional e Paradigmas de Política Externa}

Reputação internacional é um objeto do direito internacional cujo valor se dá pela atribuição positiva ou negativa a respeito de um Estado pelos demais ou, de outro modo, pela capacidade de um determinado Estado agir de acordo com seus compromissos, frequentemente chamada de confiabilidade. Dessa forma, os imperativos da política externa de um país são qualificadores de sua recepção pela comunidade internacional entre graus variáveis de confiança e desconfiança. Este artigo tem como finalidade a organização tipológica de modelos de reputação com base tanto na existência de característica cooperativa quanto no exercício de preponderância que alguns Estados gozam no ambiente internacional competitivo.

Palavras-chave: Reputação Internacional - Cooperação 
Modelos de Reputação Internacional e Paradigmas de Política Externa

\section{Abstract}

\section{Models of International Reputation and Foreign Policy Paradigms}

International reputation is a feature of international law whose value is given by other actors assigning a positive or negative rating, connected to a state's willingness and capacity to comply with its commitments - often also termed reliability. Thus, the imperatives of a country's foreign policy are the determinants of its being received by the international community with varying degrees of trust. This article establishes a typology of reputation models based on both cooperative and dominance paradigms of the reputation states enjoy in the competitive international environment.

Keywords: International Reputation - Cooperation 